\title{
El zambranismo en México, a propósito de La palabra compartida
}

\author{
Rebeca Maldonado
}

\author{
Sebastián Lomelí, Leonarda Rivera y Cintia C. Robles \\ Luján, coords., La palabra compartida. María Zambrano \\ en el debate contemporáneo. México, Porrúa, 2014.
}

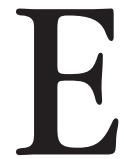

1 libro La palabra compartida. María Zambrano en el debate contemporáneo está hecho de muchas miradas y sensibilidades, desde aquella que cruza todas las perspectivas como rayo, moviéndose en todas direcciones, como la de María Antonia González Valerio, hasta la mirada que se mueve lento en las entrañas del ser, como la de Greta Rivara, o la mirada zigzagueante de Sebastián Lomelí o la mirada desafiante de Julio Quesada. En cualquier caso, este libro está hecho por autores zambranistas de última generación, por pensadores en pleno despertar, que quieren hacer ver y hacer entender cosas que afectan a nuestro ser y estructura asistidos por María Zambrano. Eduardo González di Pierro, presentador o prologuista del libro, considera que es sorprendente, en el sentido de thauma, detenerse en María Zambrano: "mujer, mujer-filósofa-desde-la-periferia", mujer filósofa desde la periferia en lengua española, mujer filósofa desde la periferia en lengua española exiliada, mujer filósofa desde la periferia en lengua española exiliada republicana, etiquetas que Zambrano deploraría, como piensa González di Pierro, porque la filosofía de Zambrano, a pesar de todo, es una filosofía que sabe, precisamente por eso, tratar con lo otro y es por ser otro, que se logra tal vez saberlo. Algo que es importante decir, es que cada uno de los autores trató de poner una "y", de manera que se pensó con María Zambrano y Foucault, "y" Edith Stein, "y" Husserl, "y" Ortega, "y" Heidegger, porque ellos han pensado desde la interconectividad, desde la profunda interpenetración en que acontece el pensar sobre María Zambrano en el debate contemporáneo. Estos escritores filósofos escriben 
desde el decir de las entrañas, eso es lo que a cada una de esas miradas les es propio, entrañable y distinguible.

Julio Quesada muestra algo fundamental para entender a Zambrano y su circunstancia. Centrado en la Agonía de Europa, Quesada encuentra que el despertar de Europa es formulado en un descubrimiento zambraniano: "que definitivamente la vida, el mundo, el ser humano, escapan de todo sepulcro". En momentos de agonía como la nuestra, despertar de la destrucción es dar testimonio. Señala Zambrano: "Ha desaparecido el mundo pero el sentir que nos enraiza en él, no”. El sentir, piensa Quesada, quiere dar testimonio de lo que estamos a punto de perder y por eso, lo que se encuentra en Zambrano no es una hermenéutica, sino testimonio de una verdad histórica, porque en esos momentos donde se juega la vida "Zambrano no tolera una objetivación de sí misma". Así asevera Quesada, "Zambrano da testimonio del naufragio, pero como superviviente del naufragio. "Nuestra filósofa propone volver a sentir, recuperar la inmediatez del mundo que se va perdiendo conforme avanza la cuantificación del ser". Zambrano tiene un incansable diálogo con la historia vivida, la cual se ha constituido también como pensamiento que separó pensar y vida, y que a su vez se ha constituido como historia sacrificial, o que se constituye a cada momento de la incapacidad de escuchar y ver al otro, o sin poder tratar con el otro.

La historia como nos revelan estos textos fue el enigma que Zambrano estuvo llamada a descifrar desde la entraña inalineable de sí misma que en lo profundo es compasión profunda y entrega al otro y a lo otro, como nos lo hace saber María Angélica Salmerón aunando Zambrano, Antígona y Weil:

Historia del sacrificio amoroso ésta de la tragedia de Sófocles, que reinventada y encarnada por Simone Weil y María Zambrano ponen en marcha a un tiempo un modo de filosofar que se considera mejor dispuesto para atender, escuchar, sentir y mirar al mundo tal y como se nos presenta: he aquí "la fuerza de la debilidad" que perfilan las razones de Antígona, pues el amor tal y como lo entienden nuestras autoras intenta poner en marcha una ética de la alteridad.

Se trata, para María Angélica Salmerón, de perfilar otros matices de la razón: fragilidad, debilidad e inclusión. Así, "Simone y María avanzan hacia el mítico camino de la otredad”. Para Salmerón siempre será imprescindible recuperar esa fuerza donante y mítica del pensar, que Simone y María traen a la filosofía desde lo que nunca pasa como es Antígona.

Cintia C. Robles presenta lo que podría ser a mi juicio más que fundamentos de una teoría de la cultura. Para Cintia Robles una cultura ha de ahincar en lo que hacemos y lo que nos pasa, es darnos cuenta que vivimos en un mundo 
o circunstancia que tenemos que salvar. Con semejante punto de partida dado por Ortega, Cintia recuerda lo dicho por González di Pierro, que desde Zambrano estamos llamados a crear conscientemente circunstancias que nos permitan vivir en simplicidad. Ésta es eso real que conforma el mundo, y lo que nos hace ser puntos de vista privilegiados sobre el mundo, mas para ello, hemos de aunar razón y sensibilidad: devenir razón poética, ella misma circunstanciada y ahí. Despertar como razón vital. Razón poética que se gesta justo desde el cultivo espontáneo de la vida, es decir, la persona: "La persona es el ser del hombre. Esa unidad radical e incomunicable que es la persona se realza a sí misma mediante la complejidad del vivir. Y vivir es con las cosas, con los demás y con nosotros mismos en cuanto vivientes". Dar lugar a un vivir circunstanciado y entregado reclaman nuestras circunstancias, desde el devenir personas. Sumamente grato leer este artículo, donde un pensar sintiente nos recupera a nosotros desde la circunstancia radical del vivir, con lo que ya queda constancia de la necesidad del abrirse a los sintientes todos.

Julieta Lizaola, se pregunta: "Cómo revertir el sometimiento y la manipulación que se traduce en la aparición de las masas, en la negación de las personas, identificadas ya por su incapacidad para identificar sus verdaderas necesidades y por su exigua capacidad de reconocerse unos en otros". Ello es imposible sin entender la estructura misma de las relaciones de dominio, pensar eso es la tarea de la filosofía. Para María Zambrano, la posibilidad de ser de la historia reside en el arquetipo originario del sacrificio, bajo el esquema de la retribución. Ésa es la relación bajo la cual los seres humanos han establecido su relación con lo divino. De manera que "la realidad continúa realizándose bajo el precepto de ofrendar parte de la vida para recibir vida", lo que se puede resumir, "en intercambiar dolor por vida". Éste es el fundamento de la polis hasta hoy en día, por lo que se revela necesario cambiar el fundamento ético de la política.

Bajo la lógica sacrificial es posible entender cómo el nuevo poder es en realidad "poder de decidir qué pueblos viven o mueren". Por lo que la expulsión, el desprecio, el exilio, la inmigración, son expresiones de la lógica sacrificial de la historia que se fundamenta en la incapacidad de escuchar, en la exigencia de la homogeneidad que finalmente abre paso a la homogeneidad de la absoluta igualdad. De ahí que el absolutismo occidental termine en los totalitarismos. Así la razón única (sin diferencia y sin otros) está acompañada de la violencia. Parecería que bajo la lógica sacrificial sólo queda la autonegación o el sacrificio de pueblos enteros que han de sacrificarse. La cultura sacrificial occidental se sostiene en una religión también sacrificial donde mueren hasta los dioses. María Zambrano, como nos relata Julieta Lizaola, anduvo siempre en la búsqueda de "una religión no sacrificial". Sin embargo, hasta donde le fue visible, sólo sacrificando se pudo tener una historia y un tiempo humanos. 
Sin embargo, la filósofa española no descansa hasta ver en medio de la herida, imagen que sorprendió a Sofía Mateos, algo de luz, pues para la filósofa española ahí cobra lugar privilegiado el amor. Como señala Julieta Lizaola: "Una nueva cultura requerirá de personas, de seres que existan en su autonomía y su interdependencia [...] Si amamos sabemos lo que queremos, por ello el amor es pilar de la objetividad, del poder elegir qué deseamos hacer, qué anhelamos realizar; es fuente de vitalidad y de ser". Para María Zambrano en lugar de somos necesariamente libres de Ortega, para ella, somos necesariamente personas. Para Julieta no ha sucedido que las democracias procuren un lugar a las personas. En toda filosofía, incluso en la Escuela de Kioto o en Heidegger, hay un verdadero responder a la pregunta, quiénes somos lejos de ese animal racional, calculador, representador, dominador y violento, para dar con un sí mismo, que en María Zambrano es la persona, que en Heidegger es Da-seyn como lugar de contienda mundo y tierra y en la Escuela de Kioto como verdadero yo capaz de ser en consonancia con todas las cosas. Pero tanto en Zambrano como en Heidegger, la que tiene que ser desplazada es la subjetividad que se piensa incondicionada. Julieta señala que urge el espíritu creador, que cobre vida en una historia ética estructurada en libertad.

Rivara Kamaji recupera este pensar-vivir desde la circunstancia, al que aludía Cintia C. Robles, y muestra cómo Zambrano va a la suya propia a través de Galdós y Miguel de Unamuno, y Cervantes. Con lo cual da la indicación para un pensar también intrahistórico, para nosotros mismos, sin perder el horizonte común, que es la conciencia de la historia sacrificial y la conciencia del pensar que ha separado pensar y sentir. Así como Misericordia de Benito Pérez Galdós fue escrita en la crisis de la restauración española, Zambrano escribe Los intelectuales en el drama de España desde los acontecimientos de la Guerra civil española (en 1938), como muchos de los autores de este libro no dejan de subrayar. María Zambrano es una pensadora de la guerra, de tiempos de oscuridad; pero, ahí en la oscuridad, María Zambrano encuentra en Benigna las raíces más profundas del sentido intrahistórico, el cual se presenta como misterio de la misericordia. Así, Zambrano observa que Galdós desciende misericordiosamente a la vida sencilla para descubrir su oscura entraña, y analiza su misterio hasta el punto en que es posible. Misericordia da cuenta del tiempo concreto, el tiempo de la vida de un pueblo (tal es el sentido intrahistórico). Razón por la cual, piensa Rivara, que Galdós sabe tratar con los otros. Y tal saber es un saber de misericordia. Se trata de un saber libre de teoría, libre del discurso teórico que piensa, dice Rivara, captar la vida toda. Es absolutamente imprescindible esta apuesta en épocas de oscuridad, el ir aunando vida, sentir y pensar. Dice Zambrano: "entre nosotros, la mente no ha sido despegada de las cosas, de la vida, por violencia alguna", tal es el pensamiento circunstanciado que Zambrano nos propone a cada momento. 
Es decir, sólo una razón que se separa de la vida, que escinde la vida, ejerce violencia. Dice Rivara: "en la novela de Galdós lo que la narración permite son seres que no se han dejado atrapar más que por la palabra que acompaña la vida sin separarse de ella, la realidad se deja saber en su infinita pluralidad". Para Zambrano, en Misericordia están "Todos los elementos esenciales de nuestro ser popular". En la novela todos se apoyan en Benigna, entre sus ejercicios de misericordia está la mentira piadosa, pues Benigna busca consuelo para los que asiste. Benigna encierra un ideario, una forma de relación con la realidad expresada en sentires. Dice Greta, Benigna "dignifica el sentido original de la misericordia; el de guardar en el corazón la necesidad del otro". De manera que aquí encontramos esa misericordia, ese saber tratar con lo otro, que Salmerón sostendría como clave de un pensar ético y de una historia no sacrificial, sino que esté basada en el amor. Entraña más profunda del pensar zambraniano es la que abre al otro.

Sofía Mateos, al acercarse al tratamiento de la luz en la pintura de Soriano por parte de María Zambrano, encuentra un concepto central: el de la herida. En María Zambrano la luz, en Soriano no es luz solar sino luz revelada que aparece como herida en la caverna. Así, de alguna manera, Sofía nos quiere decir que esa es la luz de Zambrano; su luz es "la sombra desgarrada por un rayo de luz en un instante para que el misterio de la imagen [...] aparezca”. La pintura da vida a la sombra sin borrarla, dando vida a las tinieblas. La pintura de Soriano deja ver, traspasa. Y esa es la tarea que la luz tiene en la filosofía. Porque ambos, piensa Sofía, ambos modos de luz, luz del pensamiento y luz de la pintura, son modos de acercarse a la realidad como una luz que, como la aurora, se abre como una herida y un desgarro.

Muchos indicios son los que nos han dado estos buscadores, Leonarda Rivera sigue el hilo del pensar de proveniencias de Zambrano en Azorín, Machado, Zubiri, para dar más modulación a la razón poética, pues para ella la razón poética no es sentir originario, sino que el sentir originario es uno de los pilares del pensar zambraniano, ciertamente, porque la razón poética es también razón hermenéutica, circunstancia, razón que sabe escuchar a lo otro. Para Leonarda Rivera, Zambrano lo que quiere reivindicar "es un conocimiento encarnado, ligado al cuerpo y amarrado a los sentidos", y de esa manera Zambrano es una de las voces filosóficas más críticas del concepto del racionalismo. Zambrano para quien todo pensar es insuficiente si no ahínca en el pilar del sentir originario, como piensa Leonarda Rivera, también se le hará insuficiente pronto la fenomenología.

Dice Rubén Sánchez Muñoz y cito en extenso: "El inicio de la filosofía y con ella su historia, están escritas en razón de su legitimidad epistémica, sapiencial y ontológica [...] En esta filosofía de la presencia, lo otro de la razón hace su aparición ahí donde la luz de la razón y del entendimiento no alcanza 
a explicar por su profundidad y misterio. Aparece así ese otro como sombra de la razón". El hombre que soy yo, padezco y veo, es esa sombra. Hacer visible la sombra, lo que habita en el fondo de la subjetividad, sin perder la sombra, y ser razón en sombra, es la razón mediadora que desciende a los ínferos, sin lo cual nunca podría dar cuenta de su sufrimiento y crisis. Para Sánchez Muñoz el método de Zambrano, el camino que siguió yendo más allá de la fenomenología es llevar los actos de la vida prerreflexiva a la vida reflexiva, y desde ahí dejar aparecer, de un modo que no es explicar, sino descifrar. Así, Sánchez Muñoz señala la gran distancia que separa a Zambrano de Husserl no es lo que se nos brinda originariamente, y que para la fenomenología es inatacable, sino el llevar a la sombra, a las realidades que se muestran también originariamente en sombra, a la vida consciente. O así es como interpreto a Sánchez Muñoz, pasos que en la andadura de Zambrano muestran que la filósofa, en algo fue cercana a Husserl, pero en algo más al psicoanálisis, aunque me parece que lo que se muestra en sombra, como todo lo que es verdad, dista mucho de ser fenomenológico, no es por otra cosa que Heidegger pensó en una fenomenología de lo inaparente, en una fenomenología donde lo que no se muestra es más fundamental, porque lo que se muestra pende de él.

Es difícil, en este espacio presentar pormenorizadamente las alianzas de Zambrano con otros filósofos y filósofas, sin embargo, el lector disfrutará enormemente las investigaciones profundas que los autores han hecho de Stein, de Weil, de Husserl, etcétera, para poder profundizar en María Zambrano, como es el caso de Cuitláhuac Moreno Romero, quien nos acerca primero a la escritura de sí de Foucault, a las formas de sujeción y de represión, para poder hablar de la confesión en Zambrano. La filosofía cuanto más se aleja de las pasiones, más abstracta y opuesta a la vida es. Alcanzando la máxima separación en la modernidad. El lugar de la confesión es que muestra, como sucedió en Agustín, que "puede construirse otro modo de dar cuentas de la realidad". En Zambrano, según Cuitláhuac Moreno, "lo propio de la confesión es permitir que el tiempo se abra y nos dé una salida de las circunstancias históricas en que se ha convertido el mundo". La palabra puede construir espacios de resistencia, "donde la escritura y su texto se dan como una resistencia al presente histórico desde el presente como el tiempo del acontecimiento".

Sebastián Lomelí elabora una confrontación de Zambrano y Heidegger con la metafísica. Lomelí explica por qué se acerca a ambos pensadores. En primer lugar, para él "Heidegger y Zambrano no ejecutan una crítica dura a la estetización del arte, y en cambio le conceden el estatuto ontológico de fundar un mundo histórico". Pero mientras Zambrano realiza la proeza de un pensar poético, Heidegger piensa a la poesía y al pensar como dos montañas que nunca se tocan. Ambos pensadores regresan a los griegos, Heidegger para preguntar por la verdad del ocultamiento del ser y no sólo por su aparecer, que 
es de lo que se encargó una y otra vez la metafísica, y María Zambrano regresa a Platón, para mostrar que el lugar de la verdad es el mito. La evaluación de la historia de Occidente por parte de Heidegger es la historia del olvido del ser, para Zambrano, es la historia donde "el sacrificio sigue siendo el fondo último de la historia, su secreto resorte. Ningún intento de eliminar el sacrificio, piensa, "ha logrado establecerse". En cambio, para Heidegger la historia de Occidente es la historia de un destino puesto desde el comienzo, esto es desde la visibilidad y manifestabilidad del ente, por el olvido del ocultamiento. Desde esta visión de la historia, inicia el pensar futuro. En cambio el pensar futuro en Zambrano es "atravesar el umbral que marca la diferencia entre la historia sacrificial y la otra historia de la "misericordia con lo otro olvidado". Heidegger lo entenderá como ese otro comienzo que ya no piensa el ser desde el ente, sino desde el Ereignis, como darse del ser desde su esencial sustracción, o como bien aclara Sebastián Lomelí, como darse del ser en su desocultación. Con lo cual Heidegger avanza a una comprensión en la cual en la historia del ser el ser se sustrae a favor de los entes. En este sentido, Heidegger no separará ocultamiento y desocultamiento, ni el sustraerse de la donación, de manera que no caerá en una idea de la palabra como silencio de lo sagrado, como sucede en Zambrano, que es la crítica que Oñate hace a Zambrano, el ser se da en tanto se oculta, así como tierra se abre en cuanto se cierra. Según Lomelí, para reinterpretar la idea de pensamiento como escucha conformadora de silencio, y ver a Zambrano de otra manera es necesario ir a La tumba de Antígona, donde veremos que la ley del terror, de la escisión del mundo, solo puede ser cambiada por la ley del amor que es la comunión en la diferencia. Por lo cual, el amor es una ley no excluyente, sino posibilitante.

Finalmente, el cierre de este libro lo hace María Antonia González Valerio, donde vemos un pensar que se desliza a otro lado, tal vez gracias a Zambrano, a Heidegger, a Ricoeur; María Antonia reclama, si se quería pensar la vida, pensémosla ya, sin historicismos, sin antropocentrismos. Pensemos ya, parece decir González Valerio lo que está fuera de los márgenes de la conciencia y del sujeto, esto es pensar sin más, "hay que pensar y mirar lo vivo dislocadamente, hay que ser lo vivo en una ontología posible y trazar otros mapas posibles". De este modo encuentro las más importantes resonancias para otro pensar, dice María Antonia González Valerio: "Saber tratar con lo otro y piadosamente dejar que lo vivo sea des-representado, entrañado y que recorra, pura sierpe sinuosa, los trazos invisibles de lo que hay", pues para María Antonia, en la montaña moran los dioses.

La palabra compartida es un acontecimiento que debemos pensar como don, el don de la philía y, de lo que tanto se menciona en este libro, como un ejercicio riguroso de pensar lo otro, por parte de los zambranistas en México, en un ejercicio real de desprendimiento que es marca de un verdadero pensar. 